\title{
A QUESTÃO DA CULTURA NA CONSOLIDAÇÃO DO ESTADO KOSOVAR
}

\author{
Amanda Frechiani Nascimento ${ }^{1}$
}

\begin{abstract}
Resumo
O objeto de estudo desse artigo é a sociedade Kosovar e o fenômeno de hostilidade entre as duas culturas, a albanês-kosovar e a sérvio-kosovar que atualmente a caracteriza. Esse artigo se insere no contexto do atual processo de formação do Estado nacional kosovar, tendo como marco central a declaração unilateral de independência deste Estado em 2008. Em uma abordagem interpretativa, (Geertz, 1989) dessas duas culturas, que são, a princípio, antagônicas, este trabalho visa responder à seguinte questão: O problema da etnicidade no Kosovo constitui uma barreira intransponível para o entendimento do Kosovo como Estado no sistema internacional? A metodologia utilizada será o contraste das características sociológicas do Kosovo com o modelo "do Estado essencial” formulada por Alexander Wendt (2001). Com isso, o estudo busca corroborar a hipótese de que a divisão étnica presente na referida sociedade, não representa obstáculo definitivo para o entendimento do Kosovo como Estado.
\end{abstract}

Palavras-Chaves: etnias, modelo essencial de Estado, Kosovo

\section{Abstract}

The object of study of this article is the kosova society and the hatred phenomena between the two cultures, the kosova-albanian and the kosova-serb, that currently characterize it. This article is inserted in the current consolidation process of the kosova nation State context; the central marc is the Kosovo unilateral declaration of independence in 2008. Based on an interpretative approach, (Geertz, 1989) of those two cultures, which are, at first, antagonists, this work tries to answer the following question: The problem of ethnicity in Kosovo constitutes an unbreakable barrier for the affirmation of Kosovo as a State in the international system? The methodology used is a comparison of Kosovo current sociological characteristics against the model of the "essential state" formulated by Alexander Wendt (2006). With that, the study supports the hypothesis that the ethnical separation in the referred society does not constitute a definite obstacle to the understanding of Kosovo as a State.

Key words: ethnics, the essential state, Kosovo

\footnotetext{
${ }^{1}$ Graduanda em Relações Internacionais pelo Centro Universitário Vila Velha.
} 


\section{Introdução}

O Kosovo é um país recém independente, sua declaração unilateral de independência aconteceu em 2008, apesar do início de seu processo de reconstrução e democratização nacional datar de 1999. Dentro de seu território nacional existe uma clara divisão étnica entre albaneses, que representam aproximadamente $92 \%$ da população, e sérvios que hoje respondem por $5.3 \%$ do total ${ }^{2}$. O que podemos perceber é que o Kosovo está passando atualmente por um processo de formação do seu Estado nacional, que assim como em várias outras regiões, não ocorre sempre de forma calma ou pacífica, vide a separação entre a Etiópia e a Eritréia (1993), a independência da Croácia e da Eslovênia da antiga Iugoslávia (1992), entre outros. Em alguns períodos do passado, tanto remoto como recente, a etnicidade se manifestou em violência física e social, um dos casos mais marcantes foi a Guerra da Bósnia (1992-1995). Todavia, o que interessa a esse estudo é saber se essa diversidade étnica constitui, atualmente, um obstáculo intransponível à consolidação do Estado kosovar. A hipótese defendida é a de que a cultura não se manifesta como fator de impedimento para a tal afirmação. Na realidade esse fator se apresenta como obstáculo apenas quando ocorrem esforços específicos e pontuais em direção a uma manipulação política da etnicidade. Isso é levado a cabo através do resgate seletivo de elementos históricos, que buscam justificar uma separação entre as referidas etnias. Não representa, dessa forma, uma característica natural de comportamento dos indivíduos e tampouco do governo.

\footnotetext{
${ }^{2}$ Dados oficiais do governo Kosovar de acordo com o censo de 2005. O Kosovo já tem um novo censo marcado para o ano de 2011. Mais informações podem ser encontradas no site oficial de estatísticas do governo do Kosovo: http://www.ks-gov.net/esk/eng/. (Acesso em 2 de maio de 2011).
} 
Para tanto, esse trabalho se desenvolverá em três partes. Inicialmente, serão definidos os conceitos de Estado e de cultura dentro dos quais esse estudo será conduzido. Depois, far-se-á uma análise de duas visões diferentes sobre o papel histórico das diferenças culturais na sociedade kosovar, bem como, a sua relação com a consolidação do Estado. Primeiro será feito a exposição de uma visão mais otimista, e em seguida, a sua contraposição, o realismo exacerbado. A partir de então, será lançado um olhar sobre a conjuntura recente no Kosovo. Durante esse processo será analisado se o Kosovo preenche os requisitos do "Estado essencial” construído por Wendt. Os elementos utilizados serão o atual estado da democracia e da violência no Kosovo, o status das forças armadas e o reconhecimento internacional. Durante esse processo, destacar-se-á qual o grau de obstáculo que as diferenças étnicas representam para o cumprimento de cada aspecto. Através dessa análise será possível chegar a uma conclusão sobre a capacidade do Kosovo de ser entendido, ou não, como um Estado.

\section{Conceito de Estado e de Cultura}

Visto que a análise cultural deve ser sempre o ponto de partida do cientista internacional (WENDT, 2001), essa será um elemento central desse estudo. Para entender o papel da cultura na consolidação do Estado kosovar, os conceitos utilizados, serão o de interpretação cultural desenvolvidos por Clifford Geertz (1989). De acordo com esse entendimento, de Geertz (1989), o estudo da cultura é uma ciência interpretativa em busca de significado e não em busca de leis. Isso quer dizer que se investiga o que 
motiva e o que representa para o sujeito uma determinada conduta. Assim, busca-se encontrar interpretações do comportamento e da ação social visto que é com base nestas duas noções que se articulam os elementos constituintes de uma dada cultura, tal como Geertz observa: "Deve atentar-se para o comportamento, e com exatidão, pois é através do fluxo do comportamento - ou, mais precisamente da ação social - que as fórmulas culturais encontram articulação” (1989, p.27). Por conseguinte, o locus privilegiado da análise será as instituições políticas, e as manifestações de grupos étnicos que formam o social. A cultura não será tratada, portanto, como um fator causal de acontecimentos sociais, pois, segundo Geertz (1989): “[...] ela é um contexto, algo dentro do qual eles [os acontecimentos sociais] podem ser descritos de forma inteligível - isto é, descritos com densidade.” (id; p. 24).

Tendo em vista que a influência do comportamento social na formação do Estado nacional é uma realidade para Chabal e Dalloz (1999), o conceito de cultura esbarra na noção de Estado. Sendo assim, seria impossível uma análise conclusiva da questão aqui levantada, sem definir o que esse estudo considera como um Estado. A peculiaridade das diferenças étnicas presentes no Kosovo remete a outro elemento que se deve levar em conta ao se discutir a formação do Estado, o mito da estatalidade ocidental e o papel de uma etnia única. Sobre isso, Wolfgang Döpcke (1999) aponta que um "Estado-umaEtnia” é uma criação europeia do século XIX e que a plurietnicidade é um aspecto fundamental em sociedades complexas, como está claro na citação:

A correspondência entre etnia única e Estado foi uma invenção da Europa Ocidental do final do século XIX e não representa a única forma para se construir um Estado estável. Assim, em vez de lamentar 
a multietnicidade como uma inevitável causa de conflito, temos que reconhecer sua longa tradição (não somente na África) e o seu potencial como forma para compor sociedades complexas. (DÖPCKE, 1999, p. 102)

Dentro da especialidade do objeto de estudo, a definição de Christopher Clapham (1996) do mito da estatalidade ocidental, um Estado, uma etnia, também servirá como base de análise, junto com a perspectiva de Alexander Wendt. Apesar de Clapham escrever sobre a África, suas conclusões são perfeitamente aplicáveis a esse estudo. Isso porque, tanto na África como no Kosovo existe um Estado pluriétnico que se debata para promover cooperação entre os diversos grupos dentro de um mesmo território nacional. Para Clapham (1996), muitos Estados são reconhecidos como tal e não cumprem os requisitos básicos da estatalidade, como por exemplo, o próprio domínio total do território. Dessa forma ele conclui que o conceito de Estado deve ser visto sob uma ótica relativa baseada em aspectos essenciais, que podem se apresentar em diferentes graus. Os aspectos “essenciais” para se considerar um grupo social um Estado, são, segundo Wendt (2001, tradução livre): (1) Ordenamento jurídico institucionalizado; (2) monopólio legítimo do uso da força organizada; (3) soberania; (4) uma sociedade e (5) um território.

O conceito de estatalidade será visto, portanto, sob a ótica dessas características. Como será apontado, a atual situação no Kosovo não completará perfeitamente todos os requisitos citados. Isso não será uma barreira à estatalidade, visto que como demonstrou Clapham (2006), nenhuma delas se aplica 100\% a nenhum Estado. E como Wendt (2007) apontou, o seu objetivo não era criar um modelo rígido e sim "identify what is 
commom to all discussions of how states are constructed by the states system" (WENDT, 2007, p. 214).

O primeiro requisito testado será a sociedade, visto que este é um dos aspectos mais questionados sobre a capacidade do Kosovo de ser considerado um Estado. Como notou Wendt (2001), não existe Estado sem sociedade. É o conjunto de seres humanos que seguem as mesmas regras de relacionamento que formam uma sociedade e um Estado. A problemática principal no trabalho se materializa nesse ponto. A existência de duas etnias, aparentemente rivais, dentro das fronteiras nacionais de um Estado, impede que se forme uma sociedade? A segunda seção do estudo apresentará duas perspectivas opostas sobre essa questão. Para auxiliar, também serão observadas algumas pesquisas sociais que indicam que existe uma sociedade kosovar, o que embasa o entendimento do Kosovo como um Estado.

Na terceira parte, lançaremos um olhar sobre alguns aspectos pragmáticos da atual situação do país. Será discutida a democracia, a violência interna, a declaração unilateral de independência, o monopólio interno do uso da força e o reconhecimento internacional. Durante essa observação serão destacados os graus de cumprimento dos outros aspectos do Estado essencial. Como será apontado durante o desenvolver do artigo, o Kosovo atende em maior ou menor grau a todos os parâmetros apresentados. Buscar-se-á, especialmente, elucidar que as diferenças internas não se colocam como um obstáculo à formação de uma sociedade, e, por conseguinte, não se apresentam como um impedimento à estatalidade. 


\section{Duas Perspectivas sobre a sociedade Kosovar}

O nacionalismo e o etnocentrismo são dois lados de uma mesma moeda, como bem percebeu Apostolova (1994) ao estudar o caso da antiga Iugoslávia: “O princípio étnico tornou-se um princípio de filiação política - fato que inevitavelmente levou ao fortalecimento deliberado da ideologia nacionalista.” (APOSTOLOVA, 1994, p. 86). O etnocentrismo pode facilmente se transformar em um instrumento para a legitimação do nacionalismo e vice-versa, principalmente quando transformado em política de Estado, como aconteceu no Camboja, Ruanda e Timor Leste, entre outros. (HOBSBAWN, 2008). Isso não foi diferente na antiga Iugoslávia. Entretanto, para esta região, autores diferem quanto à causa desse nacionalismo exacerbado, como é o caso de Obercshall (2000) e Timotic (2007). Alguns as atribuem a uma construção histórica conflituosa, característica da região dos Bálcãs como Apostola observa: "Na Europa Ocidental, o princípio da nacionalidade teve efeitos integrativos, ao contrário do que se observa na parte oriental do continente.” (APOSTOLA,1994, p. 85). Outros autores defendem que

o etnocentrismo apenas se veste de caráter negativo, quando instrumentalizado politicamente: “La etnicidad, pues, como sua homóloga, la nacionalidad, no se puede tomar simplesmente como esse atributo peculiar de la identidad que se convierte em la principal fuente de división entre grupos sociales contíguos" (CHABAL; DALOZ, 1999, p.97). A seguir, serão aprofundadas duas visões diferentes sobre o papel da etnicidade como causas dos conflitos nos Bálcãs, bem como suas possibilidades de superação. 
Olhando sob o viés da estatalidade, entende-se que um dos requisitos para se considerar uma sociedade presente em um determinado território, um Estado, segundo Wendt, é a própria existência dessa sociedade. Um agrupamento social de duas etnias historicamente rivais levanta dúvidas sobre a capacidade de formação de uma sociedade kosovar. Como já foi mencionado, parte desse problema provém do "mito ocidental”, que argumenta que um Estado, para ser estável, deve ser formado por uma única etnia. Entretanto, exemplos não faltam de Estados bem sucedidos formados por grupos com diferentes características culturais, por exemplo, Suíça, Bélgica e Holanda. Para Wendt (idem) a constatação da existência de uma sociedade depende de dois requisitos: (1) um entendimento comum entre as pessoas que as leva a seguir a maior parte das regras e (2) a existência de fronteiras sociais. A primeira visão apresentada defenderá a hipótese de que referida sociedade existe. Já a segunda oferecerá um contraponto à questão.

\subsection{A Possibilidade de Superação da Clivagem Étnica}

Para entender como se relaciona a questão da etnicidade e a política na região dos Bálcãs, tomaremos como ponto de partida o trabalho de Antony Obecschall de 2000: "The manipulation of ethnicity: from ethnic cooperation to violence and war in Yugoslavia”. O autor não escreveu sobre o Kosovo especificamente, mas sim sobre a Grande Iugoslávia e o seu colapso em geral. A sua pergunta principal é: Como 40 anos de cooperação (1948-1990) se transformaram em guerras sangrentas e injustas? Para 
Obercshall (2000), os iugoslavos ${ }^{3}$ possuem duas “estruturas étnicas”, uma para momentos de paz, que é caracterizada pela cooperação étnica, e uma que remonta as atrocidades da II Guerra mundial, a estrutura de crise.

A existência desses dois padrões cognitivos não representa, por si só, uma ameaça constante à paz. O que aconteceu é que a “estrutura de crise” conseguiu prevalecer durante o colapso da antiga Iugoslávia devido a dois fatores. O primeiro é a instrumentalização de estímulos à intolerância e lealdades para fins políticos. E o segundo, foi o próprio desmoronamento do Estado Iugoslavo que levou a uma questão de “dilema de segurança”, onde o medo das etnias de desaparecer levou ao investimento militar que acabou por criar mais medo e insegurança por parte da república vizinha. Essa situação adicionada as ambições pessoais de um líder, Milosevic, permitiu que a questão da etnicidade fosse transformada em bandeira política. Tal sucesso do etnocentrismo, que culminou nas guerras entre a Sérvia e a Croácia, na Guerra da Bósnia e na Guerra do Kosovo, logrou resultados graças a instrumentos de manipulação por parte das elites políticas. Isso se deu através da mídia, da educação, da literatura, e das próprias artes. Como conseqüência o diálogo e a cooperação que antes existia entre integrantes das diferentes etnias, albanesas, sérvias e croatas, viu-se extremamente reduzido o que ajudou a perpetuar o afastamento do "outro". Como bem expõe Obershall (2000):

In an interview a Serb taxi driver explained: According to several informants, when politics became contentious, it strained friendships across nationality. Either one avoided discussing public affairs and

\footnotetext{
${ }^{3}$ Considera-se Iugoslavos os antigos Estados membros da ex-Iugoslávia. Croácia, Eslovênia, BósniaHerzegovina, Sérvia e Macedônia.
} 
politics with a friend in order to remain friends, or one stopped being friends, and turned for discussion of such matters to a fellow ethnic with whom agreement was likely. (OBERSHALL, 2000, p. 993).

Aplicando esse estudo, de toda a Iugoslávia, ao Kosovo, a estrutura de crise poderia ter dado continuidade ao “ódio” dos não-sérvios para com os sérvios, devido aos massacres sofridos, pelos primeiros, em 1998. Não foi essa a situação que se engessou, pois as políticas de Estado não evocaram o etnocentrismo como meio de auferir poder. Inferese do trabalho desse autor que a etnicidade só representará uma ameaça à estabilização e democratização do Kosovo, na medida em que a "estrutura de crise” seja evocada pelos grupos sociais interessados na violência, tanto devido à bandeira ideológica, quanto como conseqüência de ambição política. O item três, sobre aplicação prática, apontará uma perspectiva que questiona essa visão sobre o que está acontecendo no Kosovo.

Existe também um estudo de Patrick Hondus (2007) que converge com as idéias de Obercshall (2000). Em seu artigo “Can Serbians and Albanians Live together?”, o autor destaca os diversos momentos históricos de convivência pacífica entre esses povos, por exemplo, na Batalha do Kosovo, em 1389, onde lutaram juntos para resistir à invasão do Império Otomano. Para Hondus (2007) o “ódio ancestral” construído sobre políticas e discursos, triunfou na época da ascensão dos nacionalismos europeus. O instrumento utilizado para isto foi a construção de mitos que legitimam o direito da territorialidade. Dessa forma, conclui-se, que para esse autor, a manipulação dos mitos pelas elites foi a causa principal para despertar um sentimento de disputa, entre os dois grupos étnicos 
estudados. Como ele afirma: "Myths offer good explanations for the present fate of a community by usually blaming others.” (HONDUS, 2007, p.7).

Fica claro, portanto, que tanto para Hondus (2007) quanto para Obercshall (2000), as diferenças étnicas existentes, e o passado violento, que marcou a relação entre esses dois grupos, só serão uma ameaça à estatalidade do Kosovo, na medida em que sejam utilizados como uma arma política. Diversos momentos de cooperação social baseados em uma cultura de elementos históricos comuns evidenciam que as peculiaridades de cada etnia não representam elementos de impedimento ao seguimento da ordem interna, que está codificada em lei. Esses elementos promovem uma clara identificação da população como kosovares. Isso quer dizer que a diferença étnica não promove uma confusão entre a idéia de fronteiras sociais, não se confunde, por exemplo, a sociedade kosovar com a macedônia, sérvia ou albanesa. Apesar de possuírem elementos comuns com essas sociedades, os kosovares possuem elementos de cultura, religião, história e língua, próprios que a caracterizam como uma sociedade pluriétnica, definindo suas fronteiras sociais. As pessoas se entendem como kosovares, a única diferença é que alguns possuem maiores atribuições albanesa e outros sérvios. Como destacou Wendt nada impede que dentro de um mesmo Estado existam diferentes "grupos de identidades” (idem, tradução livre). Percebe-se que, baseado nas pesquisas desses dois autores, não existe impedimento para que a atual configuração dos grupos étnicos no Kosovo seja entendida como uma sociedade nos termos impostos por Wendt (2001). Essa visão será ainda reforçada pela apresentação de uma pesquisa social no item 2.3. 


\subsection{As Diferenças Étnicas como Impedimento Intransponível}

Alguns autores defendem que a convivência pacífica entre albaneses e sérvios no Kosovo é altamente improvável. Em seu estudo, Serbs and Albanians de 2007, Timotic chega a essa conclusão através de uma análise da história entre esses dois povos na península balcânica. Segundo ele, a situação de discórdia se deve a dois eventos: o primeiro foi a islamização da maior parte dos albaneses entre os séculos XVII e XVIII; e o segundo, o primeiro levante sérvio contra os Otomanos de 1804 e as guerras Balcânicas em 1912-13. O primeiro marco histórico fez com que a população Sérvia, que em sua maioria não aderiu ao islamismo, se tornasse uma parte discriminada da sociedade. O referido contexto levou a uma separação cultural e social entre albanêsmuçulmanos e sérvio-católicos. Isso porque a região do Kosovo criou maiores laços de afinidade com a população albanesa e macedônia, tanto que em finais do século XIX o Império Otomano já via a necessidade de uma União administrativa que abrangesse o Kosovo, a Albânia e a Macedônia. (DREBES, 2009). Nesse período a Sérvia também fazia parte do Império Otomano, mas já buscava com maior avidez a sua total independência, enquanto o Kosovo buscava apenas privilégios de autogestão. (idem). Outro período dramático ocorreu durante as guerras balcânicas, quando a Sérvia anexou o Kosovo, no início do século XX. Timotic (2007) atribui esse evento a um sentimento revanchista por parte dos sérvios, ainda ligado ao domínio do Império Otomano, aonde o Kosovo usufruía de maiores privilégios. Ao mesmo tempo, essa nova configuração provocou o desgosto dos albanês-kosovares, como demonstrou OLIC: 


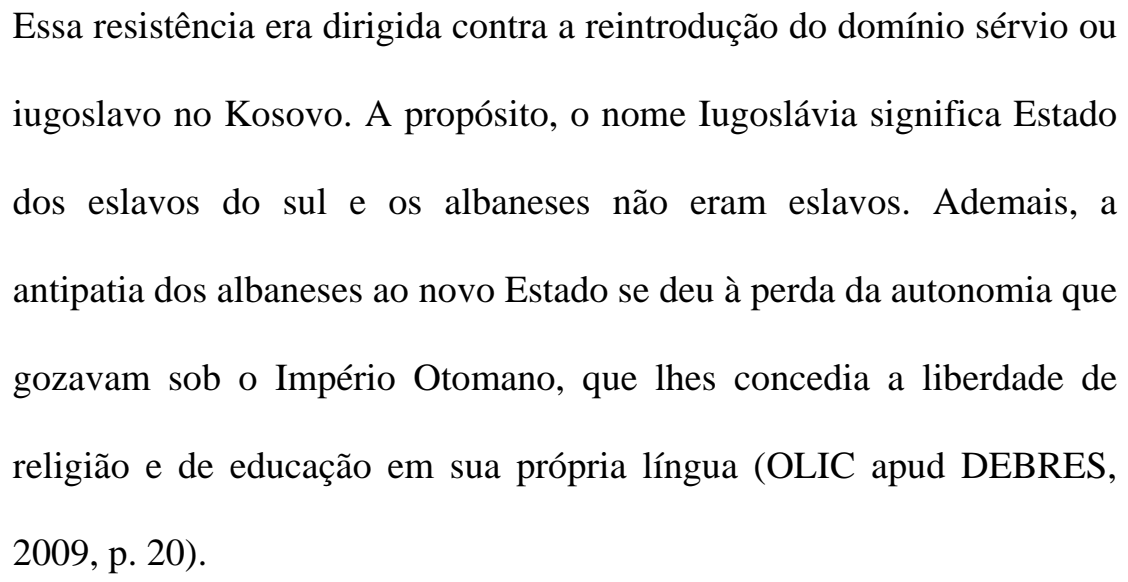

Timotic (idem) conclui deste modo, que esses levantes foram resultados naturais de um ódio cultural que sempre existiu e continuará existindo, e que os períodos de cooperação são, portanto, intervalos entre conflitos. Ele ainda destaca que a antiga convivência mista ocorreu apenas quando ainda não havia uma cisão da religião:

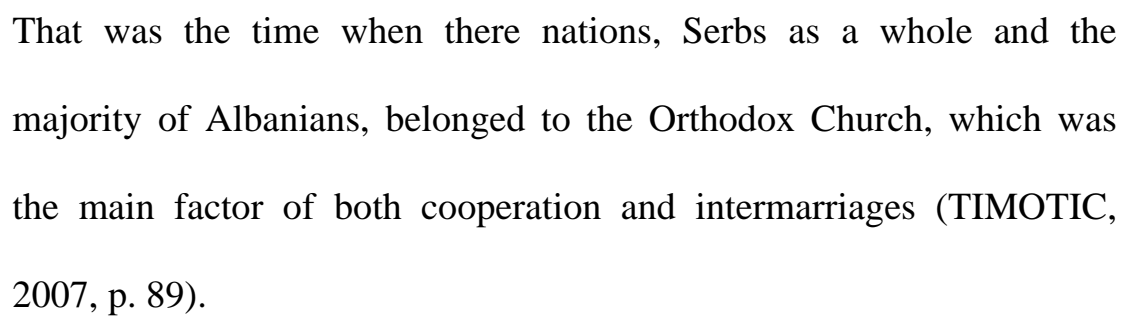

Se as idéias de Timotic estivessem totalmente corretas, nada seria capaz de apagar as lembranças de relações conflituosas para a possível reconciliação nacional formando uma sociedade kosovar. Isso porque a clivagem religiosa persiste até os dias de hoje. De acordo com Timotic, Albaneses e Sérvios, ao longo do tempo, construíram relações sociais cada vez mais tensas, e atingiram um ponto, onde a convivência estável, dentro de um mesmo Estado nacional, se tornou complexa e difícil. Vale destacar que as elites 
tiveram um papel ínfimo na análise de Timotic, que nem chega a citá-las. Na visão dessa corrente, portanto, o espírito de animosidade está presente no povo, na herança cultural, na religião e isso se reflete nos aspectos políticos e sociais, impedindo que se forme uma sociedade com um entendimento comum. Essa ausência fere o conceito de sociedade apresentado por Wendt, levando à conclusão que o Kosovo não poderia ser considerado um Estado sob a ótica desse autor.

\subsection{A Soceidade Kosovar, ela existe?}

Visto que a existência de uma sociedade é para Wendt um requisito para a existência de um “Estado essencial”, pretende-se nessa seção, através da apresentação de uma pesquisa social, reforçar o entendimento que existe uma dinâmica de relação inter-étnica no Kosovo. As interações sociais dentro do território kosovar, baseadas em valores comuns como o passado, valores culturais, normas e regras, fortalecem a concepção de que a sociedade kosovar existe.

A pesquisa demográfico-social promovido pela American Councils for International Education ${ }^{4}$, indica uma provável mudança na existência de um “ódio ancestral” natural e imutável entre albaneses e sérvios. Nesses estudos os autores, Igor Zlatojev, Tringa Indulic e Serafina Bytiqi (2008), investigaram a hipótese de que jovens albaneses e sérvios possuem a capacidade de cooperar em assuntos de interesse comum, mesmo

\footnotetext{
${ }^{4}$ A American Councils for International Education é uma associação de acadêmicos, que tem por objetivo promover o intercâmbio acadêmico pelo mundo. Para mais informações: http://www.americancouncils.org/aboutOrg.php.
} 
quando o contexto não é favorável. Na busca de descobrir se é possível a criação de uma atmosfera positiva no Kosovo, esses autores promoveram pesquisas em duas escolas de ensino médio, uma de maioria Sérvia e outra de maioria albanesa ${ }^{5}$. O que eles descobriram é que 30\% dos participantes acreditam que albaneses e sérvios irão, eventualmente, cooperar e viver em harmonia. Eles ainda constataram que, 70\% dos entrevistados pensam que os dois grupos étnicos possuem problemas e interesses comuns. Com isso, os autores concluíram que: "This percentage clearly shows that young people are aware of the other side, as well, and that they have a large level of understanding of the other side's needs and problems" (ZLATOJEV, INDULIC, BYTIQI, 2008, p. 10).

Os estudos descritos acima fornecem indícios de que as proposições de Obercshall (2000) estão corretas, pois se pode inferir que não existe no pensamento da população estudada, um ódio insuperável para com o outro. É claro que os eventos recentes de violência ainda estão vivos na memória dos dois grupos sociais. Isso fica mais claro quando se observa que $45 \%$ dos entrevistados não estariam dispostos a convidar o “outro" para sua casa, ou que, apenas 3,5\% se envolveriam em um relacionamento amoroso com um grupo social distinto. Mas o mais importante é que o estudo promovido pela American Councils of International Studies (2008), evidenciou que 82,5\% dos sérvios acreditam as manifestações étnicas violentas foram causadas por uma minoria política interessada, e que não foram respostas automáticas e naturais de grupos distintos. Isso também foi profundamente demonstrado no artigo de Shencker (2004) e Oberschall (2000) que afirmam que o ódio é politicamente manipulado.

\footnotetext{
${ }^{5}$ Esse estudo está disponível em: www.americancouncils.org/.../1017ac050708103510_8540.doc
} 
Indo além das questões étnicas em si e partindo para o modelo proposto de consolidação do Estado nacional, encontra-se na pesquisa um problema. A maior parte dos jovens sente-se inseguros em relação ao futuro do país. Apesar de isso ser uma barreira, não é de forma alguma instransponível. Percebe-se que na medida em que o governo se mostre eficiente em conter os atos de violência, como no caso de 2004, esse sentimento poderá mudar. Para que isso ocorra, Zlatajev, Indulic e Bytiqi (2008) sugerem que as instituições criem programas que promovam o diálogo e a cooperação entre as diferentes etnicidades.

Como Wendt afirmou categoricamente, “No society, no state” (Wendt, 2001, p. 209). A exposição dos trabalhos de Oberschall, de Hondus e da pesquisa social, nos permitiu inferir que existem normas, princípios e regras que fazem com que as relações que ocorram dentro do território kosovar. Essa realidade enseja a existência de uma sociedade. A ordem democrática aceita, a existência de eleições, línguas compartilhadas, laços de relacionamento inter-étnicos baseados em elementos históricos comuns e a percepção dos jovens de que existem interesses maiores a serem atingidos pela cooperação, são aspectos que permitem a constatação de que existe no Kosovo uma sociedade que se caracteriza por sua pluri-entinicidade.

\section{Aplicação Prática}

Os acontecimentos no Kosovo corroboram o entendimento de que as diferenças étnicas podem e estão sendo superadas, e, portanto, não representam um empecilho insuperável 
para a estabilização do Estado kosovar. Essa visão é oposta a análise de Timotic (2007) sugere. Como será apontado, essa perspectiva apresenta falhas para explicar muitos dos atuais acontecimentos na sociedade Kosovar, onde o ódio não é automaticamente manifestado a cada crise ou desentendimento político, e tampouco está presente nas relações sociais do dia-a-dia.

A questão do status do Kosovo ainda levanta muita polêmica. Uma breve análise da história se faz necessária para elucidar melhor a problemática. O choque da Guerra do Kosovo em 1998, com as práticas de limpeza étnica de Slobodan Milosevic, levaram a atenção do mundo para aquela região. A Organização do Tratado do Atlântico Norte (OTAN) então decidiu intervir através de bombardeios aéreos que, apesar de expulsarem o exército sérvio, matou milhares de civis, albaneses e sérvios, além de deixar o país completamente destruído. Os esforços de reconstrução física e institucional estão sendo liderados pela ONU, que estabeleceu a Missão Interina das Nações Unidas no Kosovo, UNMIK. Há também a presença da Organização para Segurança e Cooperação na Europa (OSCE), a European Union Rule of Law in Kosovo (EULEX Kosovo) e a Kosovo Force (KFOR).

Todas essas organizações estão trabalhando para a consolidação da ordem e da democracia no Kosovo. Entretanto, percebe-se que ainda se faz necessário um grande esforço tanto dos grupos internos, quanto dos externos, para atingir esses objetivos. Através da observação dos acontecimentos no Kosovo, relatados pelas tropas de paz da ONU, estudos acadêmicos e fontes oficiais, serão apresentados os aspectos que ensejam uma situação onde os cinco requisitos levantados por Wendt são alcançados. São eles: (1) a democracia, que em seu bom funcionamento, é tomada como um sinal de 
estabilização política do Estado e de institucionalização legal; (2) o estado de violência no Kosovo que evidencia a legitimidade e o monopólio do uso organizado da força; (3) a declaração unilateral de independência e o parecer favorável da Corte Internacional de Justiça (CIJ) que estabelecem uma situação de soberania e sua relação com a falta de reconhecimento externo, que como será visto, não deve ser levantado como um fator de impedimento à constatação da estatalidade do Kosovo.

\subsection{Democratização}

Como já explicitado, o maior desafio das instituições políticas balcânicas é superar o nacionalismo exacerbado como bandeira política. Esse fenômeno se iniciou de forma mais agressiva após a morte de Josip Broz, o Tito ${ }^{6}$. Como a citação de Matic (2003) demonstra:

In the 1980's radical nationalism was openly embraced by both communist elites and the fledging opposition. In that period, the national mythologies vilifying other nations while glorifying one’s own were successfully built into the foundation of political power and strategies of local leaders. Instead of democracy, "national renewal" was offered as an alternative to the previous regime (MATIC, 2003, p.

2).

\footnotetext{
6 “Tito” governou a Iugoslávia de 1953 à 1980, foi muito querido pelos povos e promoveu a integridade Iugoslava durante todo o período de seu governo. Após sua morte houve um fragmentação da antigo Estado devido principalmente ao fracasso do formato de governo baseado em uma grande autonomia administrativa entre os entes da Grande Iugoslávia.
} 
Quando se olha para o processo político nos Bálcãs se percebe que, ao contrário do que afirmou Timotic, os conflitos étnicos têm um fundo muito mais político do que cultural. Essa idéia também é compartilhada por Apostolova, 1994: “[...] é de se notar que a principal fonte deste "potencial de conflito" não é o cotidiano da convivência interétnica, mas a política dos respectivos governos.” (APOSTOLOVA, 1994, p. 85).

Nas últimas duas décadas, muitas coisas mudaram na região da Grande Iugoslávia: A Croácia, a Eslovênia, a Bósnia, a Macedônia e a Sérvia se tornaram independentes, o Kosovo passou por uma guerra sangrenta e se tornou um protetorado internacional das Nações Unidas. O objetivo da ONU é promover aos poucos a transição de instituições provisórias para um governo kosovar. Assim, realizaram-se eleições em 2001 e 2004. Em ambas foi possível atingir um governo de coligação, onde os principais partidos são: Liga democrática do Kosovo (LDK), o Partido Democrático do Kosovo (PDK) e a Aliança para o futuro do Kosovo (AKK), todos, apesar da falta de experiência, engajados na tentativa democrática, esses são indicativos importantes de amadurecimento democrático.

Durante o primeiro período de transição, o debate político ficou de fato engessado pela questão do "status" do Kosovo. Isso foi resolvido em 2008, quando este Estado se declarou independente, soberano, democrático, único e indivisível (CONSTITUIÇÃO DO KOSOVO, 2010) ${ }^{7}$. Na sua Carta Magna, estipulou como línguas oficiais o Sérvio e o Albanês, mostrando a preocupação do Estado em proteger a identidade cultural da minoria sérvia, consolidado no art. $6^{\circ}$ da constituição. Além disso, de acordo com o art. 
$3^{\circ}$ da própria constituição o Kosovo é definido como um Estado multi-étnico. Isso preenche a primeira exigência de estatalidade que foi mencionada, o Estado como defensor das minorias. A abrangência da constituição legitima a existência de um poder superior institucionalizado, visto que cria uma condição na qual a totalidade de grupos pode se identificar.

\footnotetext{
The Republic of Kosovo is a multi-ethnic society consisting of Albanian and other Communities, governed democratically with full respect for the rule of law through its legislative, executive and judicial institutions (CONSTITUIÇÃO DO KOSOVO, 2010, art. 3).
}

Outro episódio, esclarecedor da existência de uma ordem institucional legal, foi a renúncia do então presidente, Fatmir Sejdiu, no dia 27 de setembros de 2010. Ele acatou a decisão da corte constitucional, de que ele não poderia servir ao mesmo tempo aos interesses da sociedade kosovar, e ao partido político do qual é presidente, a Liga Democrática do Kosovo. Isso representou um novo desafio para as instituições democráticas, que tiveram que lidar com o fato de não terem um presidente interino no cargo. Ao mesmo tempo, percebe-se que os valores constitucionais foram cumpridos, à parte do interesse de cada grupo. Isso pode ser concluído visto que apesar de ser um momento conturbado que poderia levar à golpes de Estado ou desrespeito à ordem constitucional, como aconteceu por exemplo no Haiti, na Nigéria, no Congo, em Honduras, na Costa do Marfim, entre outros, o presidente aceitou a decisão da Corte e foi substituído por um presidente interino, Jakup Krasniqi. 
Ora, o que se vê hoje é uma implantação do Estado de Direito, onde as diferenças são respeitadas e internalizadas pela própria constituição. O que se pode deduzir é que as antigas causas, de manipulações étnicas, que deram origem as disputas entre os diversos grupos sociais no passado, estão perdendo o ímpeto político e, conseqüentemente, desaparecendo. Essa afirmação foi recentemente evidenciada através do último processo eleitoral no Kosovo. A beira, mais uma vez, de uma crise política, o então presidente, Jakup Krasniqi dissolveu o parlamento em finais de 2010 e convocou eleições para o início de 2011. O novo presidente eleito foi Behgjet Pacolli, entretanto, em março a corte constitucional declarou que as eleições foram ilegais, e o Sr. Pacolli pacificamente renunciou ao cargo acatando a decisão da Corte (REUTERS, 2011). O Kosovo se encontrou então em meio a uma crise, cuja solução foi rapidamente encontrada. Já em princípios de abril através de uma conciliação entre o principal partido de direita (LDK) e a aliança de esquerda (PDK) que elegeram a primeira presidente mulher, Atifete Jahjaga . (TRUST, 2011)

Sônia Rodrigues (2008), em seu trabalho “A transição democrática no Kosovo”, também já havia notado indicativos de amadurecimento democrático e concluiu: "No que respeita ao processo de transição democrática conduzido sob a autoridade da UNMIK, registram-se progressos consideráveis na estabilidade regional e no nível de democratização no Kosovo face à realidade de 1999. (RODRIGUES, 2008, p. 94).

Constata-se, dessa forma o respeito à ordem constitucional, reforçado pela existência uma constituição pluriétinica que estabelece as normas, regras e princípios de relação entre os membros da sociedade que a formam. Essa configuração evidencia uma Ordem 
Institucional Legal e uma soberania interna, aonde, como requisitado por Wendt (2007) é o locus político de autoridade e de tomada de decisão.

\subsection{Manifestações de Violência}

Um dos conceitos mais consolidados sobre Estado é a concepção de Weber, de que um Estado é aquele que detém o monopólio do uso legítimo da força dentro de suas fronteiras (BOBBIO et al, 1997). Quando se fala de força, se refere tanto a força de repressão contra violência interna, quanto à capacidade de se defender de possíveis ameaças externas. Dessa forma pretende-se a seguir analisar ambas as dimensões.

As manifestações de violência entre as duas etnicidades, que apesar de terem diminuído com a presença da UNMIK, ainda persistem. Um episódio nos chama a atenção, em especial, por ter acontecido após um breve período de estabilidade entre 1998 e 2004.

Em março de 2004, uma onda de violência se espalhou pelo Kosovo. Esse evento foi desencadeado por protestos contra o estupro e o assassinato de três crianças albanesas (SHENCKER, 2004). É de se esperar que situações dessa natureza ocorram em todas as sociedades, porém, o que tornou esse ato de atrocidade tão “apelativo” foi a rápida e intensa escalada da violência entre sérvios e albaneses, que necessitou da intervenção da UN Police e da KFOR. No final das hostilidades, trinta sérvios foram mortos, trinta igrejas e 360 casas destruídas, além de 3600 pessoas feridas. 
Na tentativa de entender as causas de tamanha destruição, a European Centre for Minority Issues (ECMI) ${ }^{8}$ desenvolveu um estudo intitulado: "Violence in Kosovo and the Way Ahead (2004). Nesse trabalho, Harald Shencker (2004), demonstra que os partidos políticos ficaram tão surpresos quanto a sociedade internacional com os eventos. Isso poderia levar a crer que o problema no Kosovo se encontra dentro da própria diferença cultural, como defendeu Timotic (2007). Entretanto, quando se analisa com mais profundidade, percebe-se que os jovens que participaram dos atos de vandalismos, barricadas e violência física entre etnias estavam sendo manipulados através da mídia e de redes sociais. Shencker (2004) admite que não foi de fato possível chegar às raízes motivadoras, mas conclui que: “The events in both Kosovo and Serbia show that there is a critical mass of mainly young people who can easily be mobilised and utilised for atrocities by whoever has the interest to do so" (SHENCKER, 2004, p. $6)$.

Isso corrobora muito mais a tese de Obershall (2000), que defende que o "padrão de crise”, só se sobressai quando influenciado por forças nacionalistas de nacionalismo exacerbado. Sustenta ainda dois pilares do "Estado essencial", a existência de uma sociedade com entendimento comum que segue a maior parte das leis, visto que condenou veemente os ataques. Além disso, destaca-se a capacidade do Estado, de fazer o uso legítimo da força para restabelecer a ordem e garantir o cumprimento da lei através da coerção. O simples fato de haver violência étnica não ameaça o monopólio do uso da força pelo Estado, visto que, como levantado por Wendt, as forças precisam

\footnotetext{
${ }^{8}$ A European Centre for Minority Issues (ECMI) é uma organização intergovernamental, que promove pesquisas políticas com enfoque em na relação de minorias e maiorias na Europa. O estudo citado pode ser encontrado em: < www.ecmi.de/download/brief_10.pdf>
} 
gozar apenas de dois requisitos: não serem rivais e estarem unificados, ou seja, entenderem a ameaça de forma coletiva. (2001, p. 204, tradução livre). Essa é a atual configuração encontrada no Kosovo.

É de se notar que existe a presença de forças não kosovares dentro do território, como a KFOR, a UNPOLICE, a EULEX e outras instituições. Contudo, apesar de ter que dividir autonomia com esses atores, eles não representam uma ameaça ao Estado Kosovar. Todos eles reconhecem o Estado de direito no Kosovo e trabalham para sua estabilidade e legitimação de forma cooperativa. Cumpre-se assim as exigências de Robert Jackson (1990), outro estudioso da estatalidade, quais sejam de que o Kosovo seja capaz de manter a sua independência e gozar do monopólio do uso da força dentro da totalidade de seu território. Essa conclusão é compartilhada por Wendt: “This suggests the possibility of decentralized or "international" state structures that do not have a single head but are still capable of institutionalized collective action” (2001, p. 205)

Claro que se deve levar em conta que, como mencionado, existem diversas forças mantendo a ordem e a estabilidade interna no Kosovo e não se pode prever como a sociedade kosovar funcionará após a saída desses órgãos. Por outro lado essas outras “forças armadas” atuam em conjunto, ou seja, estão unificadas, e não contra o governo kosovar, além disso, não possuem a pretensão de se estabeleceram na região eternamente. A KFOR, por exemplo, atua cooperando com a polícia local sob o mandato das Nações Unidas. Além disso, representam um elemento de transição que desaparecerão ao longo do tempo, como a própria KFOR estabelece: 


\begin{abstract}
Since then, the security situation has continued to improve. As a result, on 11-12 June 2009, NATO defence ministers decided to gradually adjust KFOR's force posture to what is called a deterrent presence. This means that, when appropriate and according to the evolution of events, over time NATO will reduce the number of forces on the ground, with the remaining forces in theatre progressively relying more on intelligence and flexibility (KFOR, 2011).
\end{abstract}

Referida redução já se pode até mesmo constatar desde a declaração unilateral de independência. Com a diminuição da violência, as atribuições da KFOR estão paulatinamente sendo reduzidas. Em fevereiro de 2010 houve uma redução das tropas para aproximadamente 10.000 soldados e se planeja provocar uma nova redução para 5000. Junta-se a isso o fato de que inexistem no Kosovo forças armadas organizadas competindo por território dentro da sociedade kosovar. Conclui-se, com descritos acim, que se configura no Kosovo uma realidade de monopólio do uso legítimo da força pelo Estado.

\title{
3.3. Declaração Unilateral de Independência e Reconhecimento Internacional
}

Em 17 de fevereiro de 2008 o Kosovo declara sua independente. Coloca-se em cheque a sua soberania devido a falta de reconhecimento internacional. Apesar de se mostrar como um ponto de fraqueza, o processo de reconhecimento internacional, ainda que incompleto, não se apresenta como um fator de impedimento para o entendimento 
cognitivo do Kosovo como um Estado no sistema internacional. Isso porque, como apontado por Robert H. Jackson (1996) e Wendt (2001), é necessário, segundo esses autores que não se confunda reconhecimento com soberania. Jackson (idem) destaca que os Estados que possuem o que ele chama de Soberania Positiva, são aqueles que possuem o monopólio interno de uso da força em seu território e sob a sua população, além de gozarem da capacidade de se proteger contra ameaças externas, mesmo que para isso necessite da ajuda de seus aliados. Wendt, 2001, é ainda é mais flexível quanto à sobernia interna, exigindo apenas: "that the State is the supreme locus of political authority in society. (p. 206).” Ora, se esses são os pré-requisitos para que se considere a soberania interna e externa de um Estado, a declaração unilateral de independência, como será argumentado, e alguns outros elementos, fazem com que o Kosovo os preencha.

A declaração foi feita de forma unilateral, entretanto, isso não a deslegitima, como bem apontou RODRIGUES (2008):

A Declaração de Independência proclamada pelos órgãos máximos das estruturas institucionais provisórias do Kosovo foi $<<$ unilateral $>>$ até certa medida. Com efeito, a declaração foi concertada com a EU e os Estados Unidos, e a aprovação da Missão da União Europeia para o Estado de Direito no Kosovo (EULEX), a 4 de Fevereiro, foi igualmente um prenúncio de uma independência anunciada (RODRIGUES, 2008, p. 90). 
Desde então, o Kosovo foi reconhecido por setenta países, incluindo Estados Unidos, Alemanha, França, Reino Unido e Portugal. Em 2010, a Corte Internacional de Justiça deferiu que:

The Court has concluded above that the adoption of the declaration of independence of 17 February 2008 did not violate general international law, Security Council resolution 1244 (1999) or the Constitutional Framework. Consequently the adoption of that declaration did not violate any applicable rule of international law. (CORTE INTERNACIONAL DE JUSTIÇA, 22 jul. 2010). ${ }^{9}$

O ponto de inflexão da questão recai sobre a recusa da Sérvia em reconhecer a nova República kosovar. A maior parte dos outros países, como Espanha, Rússia e China, para citar os mais importantes, e que possuem minorias reivindicando autonomia, não aceitarão o reconhecimento do Kosovo antes do reconhecimento da Sérvia. Por outro lado, sua inserção na ordem internacional tem mostrado claros sinais de otimismo, a começar pelo deferimento da Corte Internacional de Justiça, em 2010, passando pela retomado do diálogo com os sérvios e pela atuação do Kosovo como ator no sistema internacional e culminando com a tentativa de entrada na ONU. Aqui devemos destacar dois pontos. Primeiro o fato de a declaração unilateral de independência ter sido proferida pela Assembléia kosovar, o que reforça a soberania interna, mostrando que existe um locus político de autoridade de onde emana a autoridade. O segundo aspecto diz respeito à soberania externa, que é considerado como a ausência de qualquer outra

\footnotetext{
${ }^{9}$ O completo texto da decisão da Corte Internacional de Justiça, pode ser acessado no site: < www.icjcij.org/docket/files/141/15987.pdf>
} 
autoridade acima da do próprio Estado. Mais uma vez destaco que ausência do reconhecimento da totalidade ou maioria dos Estados não enfraquecem essa soberania, como afirmou Wendt: "States can have external sovereignty even if it is not recognized by other states" (WENDT, 2001, 208).

No que tange à ameaça externa por parte da Sérvia alguns pontos devem ser esclarecidos. Primeiramente esse país tem claras aspirações de fazer parte da UE. Porém tal adesão terá que passar pelo reconhecimento do Kosovo como Estado independente. Em 27 de setembro, em uma reportagem no Media Monitoring da UNMIK, uma jornalista defendia:

Several dailies quote European Stability Initiative analyst Verena Knaus as saying that Serbia won't be able to join the European Union without accepting the reality of the independent state of Kosovo. "No one in the European Union is willing to import a problem that is similar to that between Turkey and Cyprus,” said Knaus (UNMIN, 2010).

Os relatórios da UNMIK sobre esse assunto não se mostram muito otimistas. Apesar da cooperação entre Pristina e Belgrado existir em alguns campos, como a busca de desaparecidos, o diálogo do reconhecimento continua estagnado. No entanto, o relatório de 29 de julho acrescenta: “[...]UNMIK facilitation has, in most cases, allowed to reconcile the seemingly incompatible demands of the two sides, thus providing a concrete contribution to the development of regional cooperation initiatives" (UNMIK 
REPORT, 2010) ${ }^{10}$. Vale lembrar que para conseguir ingressar na ONU, o Kosovo precisa ser recomendado pelo Conselho de Segurança, do qual Rússia e China fazem parte com direito a veto, e obter uma maioria de 2/3 na Assembléia Geral, o que hoje corresponde a 128 membros $^{11}$.

Mesmo notando-se que as negociações se dão de forma lenta, já se pode observar que há por parte dos Sérvios uma disposição ao diálogo. No dia oito de setembro de 2010, a Sérvia em conjunto com 27 membros da União Européia patrocinou um documento (GA/10980) na Assembléia Geral da ONU, que foi adotado imediatamente. Ele tomava conhecimento da decisão da Corte Internacional de Justiça de declarar a Independência Unilateral do Kosovo como legal, sob os parâmetros internacionais. Este mesmo documento, vê com bons olhos o papel da União Européia para facilitar o diálogo entre as partes.

Percebe-se que o Kosovo também é capaz de manter a sua integridade, mesmo que para isso conte com seus aliados Europeus e da ONU. Nesse sentido também vale destacar que apesar da ausência do reconhecimento formal da Sérvia, ela não apresenta uma ameaça iminente ao Kosovo, visto que devido aos interesses políticos de integrar a UE, a possibilidade de um ataque por parte desse país é quase nula. Dessa forma pode-se mesmo inferir que existe um reconhecimento da Sérvia, isso é possível quando se entende que o reconhecimento implica uma disposição de "live and let live. (WENDT, 2001, p. 209). Adiciona-se a isso o fato de que o Kosovo atua como um Estado perante

\footnotetext{
O 10 Relatório completo pode ser encontrado em:<http://www.unmikonline.org/UNMIKONLINE2009/misc/docs/sc-reports.htm>.

11 Uma explicação mais extensa pode ser encontrada no site das Nações Unidas no endereço: <http://www.un.org/en/ga/>.
} 
a Sérvia quando esses se engajam em negociações conjuntas através de vias diplomáticas institucionalizas.

A conclusão a que se chega é de que a soberania do Kosovo, tanto interna quanto externa é inquestionável, independentemente do maior ou menor grau de coesão que se atribua a ela. Como bem apontou Clapham (1996): “In retrospect, it would be fairer to conclude that all states rely on some combination of external recognition and domestic power, even though the ingredients of the mix may vary sharply from one case to another" (idem, p. 2).

É preciso que se esclareça que o requisito território foi intencionalmente excluído deste estudo por motivos de pragmatismo. Como se elaborou desde o início, a questão em cheque no Kosovo era a possibilidade de existência de uma sociedade. Entendeu-se que essa dúvida também ameaçava os outros aspectos, mas não o aspecto territorial que parece bem definido após o fim das hostilidades com a Sérvia em 1999.

Buscou-se argumentar nessa seção, que apesar de o Kosovo não gozar hoje de extenso reconhecimento internacional, muitas forças sociais estão atuando para uma provável mudança desse quadro, dentre as quais, a declaração positiva da Corte Internacional de Justiça, o reconhecimento por setenta Estados, a vontade da Sérvia de fazer parte da União Européia, e, por conseguinte, a necessidade de reconhecer o Kosovo e as possibilidades de diálogo entre Belgrado e Pristina. Além disso, esse país atua na cena internacional com atribuições de um Estado, promovendo negociações, influenciando agendas e discursos e firmando tratado, como por exemplo, um tratado comercial com a Macedônia em 2011. A falta de uma homogeneidade interna de etnias não impede que o Kosovo cumpra sua situação de Estado, assim como definida no início desse artigo. O 
Kosovo não é um Estado reconhecido dentro dos parâmetros do "mito ocidental", todavia, cumpre outros aspectos, soberania interna e externa, monopólio do uso da força, capacidade de manutenção de suas fronteiras, que permite que ele seja entendido como tal.

\section{Conclusão}

Para responder a pergunta levantada no início desse trabalho, partiu-se da hipótese de que a existência de duas etnias diferentes, albanesa e sérvia, dentro do Kosovo não se constitui em obstáculo instransponível à constatação da existência de uma sociedade kosovar e para a consolidação do Kosovo como Estado. Conseguiu-se corroborar tal assertiva adotando-se o modelo teórico de Obercshall (2000), que defende que, apesar de um passado com eventos conflituosos entre essas duas etnias, o que chama de “padrão de crise”, não é nem natural nem insuperável. Esse modelo foi ainda sustentado pelos estudos históricos de Hondus (2010) que demonstraram que em diversos momentos do passado o sentimento de união sob a égide de pertencer à identidade kosovar, fez com que esses grupos atuassem de maneira conjunta. Pode-se concluir que sem a invocação dessa estrutura as duas etnias vivem em harmonia sendo regidas pelas mesmas leis dentro das fronteiras nacionais, cumprindo as exigências de Wendt (2001). A hipótese de Obercshall (2000) parece ser reforçada, pelo menos até o momento, pelo atual estado de paz relativa e democratização do Estado Kosovar, onde, apesar de incidentes pontuais, as duas etnias estão dispostas a dialogar. Outro ponto positivo foi a 
pesquisa social-demográfica promovida pela American Councils for International Education, de mais legitimidade as propostas de Obercshall (2000), quando foi evidenciado, ainda mais, o entendimento cognitivo do outro como pertencente a um todo maior. Dessa forma pode-se inferir que, visto que as disputas étnicas não definem totalmente a identidade dos grupos estudados, e não são insuperáveis. A cooperação pode e deve ser instigada através da promoção da interação entre as duas etnias visto que existe um entendimento mútuo de pertencer a um grupo social maior, a sociedade kosovar. Além disso, a constituição do Kosovo de 2008 demonstra que esses valores estão agora internalizados no Estado de direito, reconhecendo a multietnicidade do Estado, evidenciando a ausência de impedimentos para a existência de uma sociedade.

Quanto à análise dos quatro pilares sob os quais se deve definir um Estado-Nação, citados anteriormente, percebeu-se que o Kosovo cumpre em menor ou maior grau com todos os requisitos. Aqueles que se apresentaram de forma mais satisfatória foram: a vontade do Estado de proteger as minorias, compreendidas na constituição de 2008, e a capacidade de superação das crises políticas por meio do arcabouço institucional do Estado sem se remeter às diferenças étnicas. O que se percebe é que o Kosovo caminha por um processo, talvez único, que vem se dando de forma lenta e gradual, mas também estável e eficiente.

O requisito de existência uma Ordem Legal Institucionalizada foi demonstrada pela adoção de uma constituição democrática que é observada em momentos de crise política. Essa situação é reforçada quando se observa a existência de partidos políticos comprometidos com o ordenamento jurídico interno e não com o antigo nacionalismo que regiam as relações políticas nesse Estado. No que diz respeito ao monopólio do uso 
da força dentro do Estado nacional, o Kosovo cumpre com o requisito na medida em que possui forças armadas internas e externas unificadas e não-rivais. Constata-se que esse monopólio é divido com a ONU Police, a KFOR, e a EULEX, mas que essas forças agem em cooperação com o Estado kosovar. Além disso, são de aspecto temporário, visto que esses órgãos só estão presentes para garantir a estabilidade e a transição pacífica, o que acaba por reafirmar a consolidação do Estado e já prevêem a diminuição de sua atuação.

Como último pilar abordou-se o tema da soberania. Nesse ponto, pode-se concluir que o Kosovo possui soberania interna na medida em que existe um locus único de onde emanam as decisões políticas que são aceitas pela sociedade, como aconteceu na ocasião da declaração unilateral de independência. A falta de reconhecimento internacional, como demonstrado não ameaça a situação de soberania externa da qual goza o Kosovo, visto que esse Estado tem a capacidade de proteger suas fronteiras de ameaças externas. Além disso, atua no sistema como um Estado, assinando tratados e se engajando em negociações que ensejam esse status.

Não se busca argumentar que o Kosovo representa um Estado-Nação inquestionavelmente consolidado, mas, sim, que reúne todos os elementos do "Estado essencial” levantados por Wendt (2001), para assim ser entendido no sistema internacional. E, principalmente, explicitar que as diferenças étnicas dentro do Estado não impedem a constituição de uma sociedade kosovar e conseqüentemente a existência do Kosovo como um Estado no sistema internacional.

De fato quando se olha para os fatos, muito da história e do presente do Kosovo são marcados por atos de violência entre as etnias. Mas como foi demonstrado desde o 
CADERNOS DE RELAÇÕES INTERNACIONAIS, v. 4, n.1, 2011

início desse trabalho não se deve utilizar a ação social em si como o objeto privilegiado de análise, e sim buscar as forças que agem por traz do ato em si (Geertz, 1989). Quando isso é feito, percebe-se que os motivos para os atos que podem desestabilizar a sociedade kosovar são instigados ao invés de estarem de fato incrustados no padrão cultural e na identidade de cada indivíduo, mas eles não minam a própria existência dessa sociedade. 


\section{Referências Bibliográficas}

ALERTNET. Kosovo parties agree to end political deadlock. Disponível em: $<$ http://www.trust.org/alertnet/news/kosovo-parties-agree-to-end-political-deadlock/>. Acesso em: 05 de maio de 2011.

APOSTOLOVA, M, S. Iugoslávia: Crônica de uma crise. Revista Brasileira de Política Internacional, Vol. 47. Brasília: 2004, p. 82-105.

BYTYQI, I; INDULIC, T; ZLATOJEV, I. Inter-Ethnic Understanding Among Young Serbians and Albanians. American Councils for Internacional Education. Disponível em: <www.americancouncils.org/.../1017ac050708103510_8540.doc>. Acesso em: 9 set. 2010.

BOBBIO, Norberto; MATTEUCCI, Nicola; PASQUINO, Gianfranco. Dicionário de política. 10. ed. Brasília: Editora Universidade de Brasília, 1997. 2 v.

CHABAL, P.; DALLOZ, J. (1999). Africa Camina: El desordem Como Instrumento Político. Barcelona: Bellaterra, 2001.

CLAPHAM, C. (1996). African and the international system: the politics of state survival. Cambridge University Press. 1996.

CONSTITUTION Of the Republic of Kosovo. Disponível em: <http://www.unigraz.at/opv1www_constitution_kosovo.pdf $>$. Acesso em: 27 set. 2010.

DEBRES, J. S. A Independência do Kosovo: A Ccontroversa Emergência De Um Estado Na Ordem Política Internacional. 2009. 104p. Monografia. Pontifícia Universidade Católica do Rio Grande do Sul. Porto Alegre. Disponível em: $<$ www.pucrs.br/direito/graduacao/tc/tccII/trabalhos2009.../josue_drebes.pdf $>$. Acesso em: 28 jul. 2010. 
DOPCKE, W. (1999). A Vida Longa das Linhas Retas: cinco mitos sobre as fronteiras na África Negra. Revista Brasileira de Política Internacional, Vol. 42, no1. Brasília: Jan/Jun, 1999.

GA/ 10980. United Nations General Assembly. Disponível em: <http://www.un.org/News/Press/docs/2010/ga10980.doc.htm>. Acesso em: 14 set. 2010 .

GEERTZ, C. A interpretação das culturas. Rio de Janeiro: LTC, 1989. 323 p.

HOBSBAWM, Eric J. Globalização, democracia e terrorismo. São Paulo: Companhia das Letras, 2008. 182 p.

HONDUS, P. Can Serbs and Albanians Live Together? Western Balcans Security Observer no 4. Belgrado, Jan/Mar, 2007. Disponível em: <www.ccmrbg.org/upload/document/serbs_and_albanians_milorad_ti.pdf>. Acesso em: 5 set. 2010.

IGNATIEFF, M. A Tragédia dos Bálcãs. Política Externa, vol. 2, n. 2, São Paulo 1993.

INTERIM Administration Mission in Kosovo. UNMIK Online. Disponível em: <http://www.unmikonline.org/>. Acesso em: 23 set. 2010.

JACKSON, H. R. Quasi-States: Soverignty, International Relations and the Third World. Cambridge [England]; New York: Cambridge University Press, 1996. Cambridge studies in international relations, 12). 
KOSOVO President Resigns. REUTERS. Disponível em: <http://www.reuters.com/article/idUSTRE68Q2WE20100927>. Acesso em: 28 set. 2010.

MATIC, V. Unbreakable Bond: Serbs and Kosovo. Public International Law \& Policy Group, $\quad 2003 . \quad$ December Disponível em: <http://www.publicinternationallaw.org/publications/reports/UnbreakableBondSerbsand Kosovo1203.pdf $>$. Acesso em: 8 set. 2010.

OBERCSHALL, A. The Manipulation Of The Ethnicity: From Ethnic Cooperation To Violence And War In Yugoslavia. Ethnic and Racial Studies Volume 23 Number 6 November 2000 pp. 982-1001. Disponível em: <www.cla.wayne.edu/polisci/dubrovnik/readings/oberschall.pdf $>$. Acesso em: 1 set. 2010 .

OTAN. Nato's role in Kosovo. Disponível em: $<$ http://www.nato.int/cps/en/natolive/topics_48818.htm>. Acesso em: 05 de maio de 2011.

REUTERS. Kosovo President Elections Was Ilegal, court rules. Disponível em:<http://www.reuters.com/article/2011/03/28/kosovo-president-court idUSBYT85574820110328>. Acesso em: 04 de maio de 2011.

REPUBLIC of Kosova. Assembly. Disponível em: $<$ http://www.mfaks.net/Ministry/Mission/tabid/151/Default.aspx?page=2,1>. Acesso em: 22 set. 2010.

Government. Disponível em: <http://rks-gov.net/sq-AL/Pages/Fillimi.aspx>. Acesso em: 10 set. 2010.

RODRIGUES, S. A Transição Democrática no Kosovo. Relações Internacionais, dez. 2008, no. 20, $\quad$ p. 85-95. Disponível em: < http://www.scielo.oces.mctes.pt/scielo.php?pid=S164591992008000300008\&script=sci_arttext>. Acesso em: 3 set. 2010. 
SHENCKER, . Violence in Kosovo and the Way Ahead. European Centre for Minority Issues. Alemanha, 2004, no. 10. Disponível em: <www.ecmi.de/download/brief_10.pdf>. Acesso em: 11 set. 2010.

TIMOTIC, M. Serbs and Albanians. Western Balcans Security Observer no 5. Belgrado, Abril/Jun, 2007. Disponível em: <http://www.ccmrbg.org/upload/document/serbs_and_albanians_milorad_ti.pdf $>$. Acesso em: 20 set. 2010.

UNITED Nations Member States. United Nations. Disponível em: <http://www.un.org/en/members/about.shtml>. Acesso em: 16 set. 2010.

WENDT, Alexander. Social theory of international politics. Cambridge, UK; New York: Cambridge University Press, 2001. 429 p. 